\title{
Research allocations: The long-standing basic/strategic debate
}

Published at www.cmaj.ca on Apr. 23

I n 1917, French physicist Paul Langévin began conducting experiments on ultrasonic energy. His work inspired others, including Dr. Karl Dussik, an Austrian neurologist, who in the 1940s became the first doctor to use ultrasound in medical diagnosis. The curiosity of one researcher about basic scientific principles eventually led another to create a medical tool of immense value.

This is but one example cited by researchers to illustrate the importance of funding basic research, even if no practical applications of that research are apparent.

"Investigator-driven research is very important," says Roy Cameron, professor of applied health sciences at the University of Waterloo in Ontario. "We need to understand nature in all its dimensions, because it's important in its own right and because it opens the door to solving problems that we face."

Research is generally divided into two streams. There is basic research, which goes by many other names as well: curiosity-driven, investigator-initiated, discovery-based and "blue skies." The goal of this type of research is not to achieve a short-term impact or a practical goal, but rather to further knowledge and understanding of the physical world.

The second stream is referred to as strategic research, though it too has other monikers: goal-oriented, marketdriven or targeted. This type of research typically aligns with the national health priorities of the country that funds it.

In Canada, basic research receives the lion's share of funding, though different funding bodies vary in how they allocate money to each stream. A 1999 analysis of several national and Quebec funding bodies found that, overall, $72 \%$ of their grants went toward basic

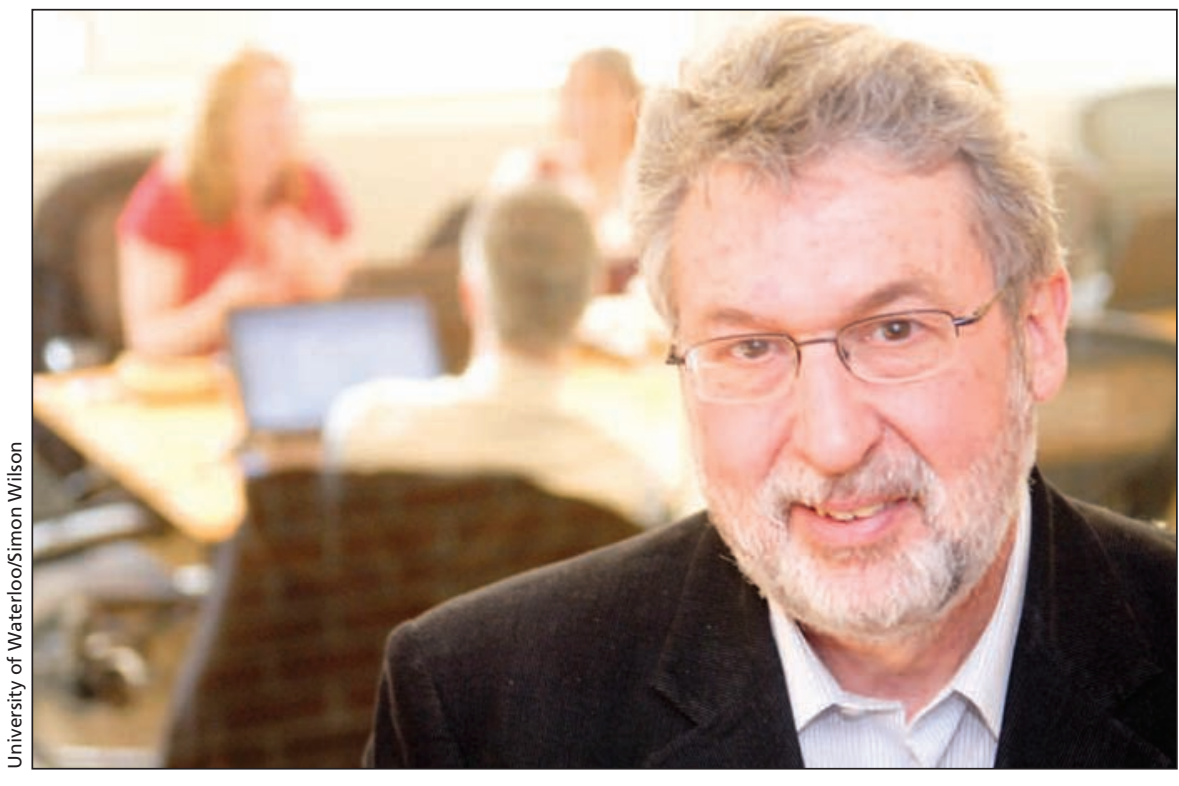

Roy Cameron, professor of applied health sciences at the University of Waterloo in Ontario, who says in defence of basic science that we need to understand nature, because it's important and because it opens the door to solving problems.

research, a drop from $82 \%$ in 1983 (www.ost.uqam.ca/Portals/0/docs/ob_a rch/Bulletin1_2a.pdf).

Some funding bodies, however, were investing little in basic research. In Quebec, the Fonds de la recherche en santé, for instance, dedicated only $34 \%$ to curiosity-driven research, and the Conseil québécois de la recherche sociale allocated a mere 5\%. The Fonds pour la Formation de chercheurs et l'aide à la recherche, on the other hand, devoted $97 \%$ of its funding to basic research.

Canada's major public funder of health research, the Canadian Institutes of Health Research (CIHR), currently puts $70 \%$ of its grant money toward basic research, the remaining 30\% going to strategic research. In the curiosity-driven stream, grants are awarded based on excellence, not anticipated outcomes.

"We have a process of selection that is based purely on excellence, which is determined by peers," says Pierre Char- trand, vice-president of research at CIHR. "We can't dictate to researchers what research they should be doing."

According to Chartrand, providing ample funding for investigator-driven research is the only way to create a strong and vibrant research community. If that community didn't exist, he says, there would be no pool of talent to draw from to conduct strategic research. Many Canadian researchers agree, claiming that basic research, in the long run, also pays off in practical ways.

"I completely agree with the CIHR position that you still need to fund basic research in all areas, and that you need a very strong base level of funding," says Bruce Verchere, head of the diabetes research program at the Child and Family Research Institute in Vancouver, British Columbia. "Many Nobel Prizes and cures and therapies came from health research that wasn't targeted."

It should come as no surprise, of course, that many health researchers favour an allocation model that allows 
them to follow their own interests more often than someone else's agenda.

"If you are getting most of the money, you think the allocation is sensible, and if you are not getting most of the money, you think the allocation is irrational," says Jeremy Shiffman, an associate professor of public administration at Syracuse University in New York who researches the political dynamics of health and policy-making.

But not everyone agrees that a proper balance has been reached between basic and strategic research funding.

In May 2009, Harvey Weingarten, president and vice-chancellor of the University of Calgary in Alberta, wrote that politicians, public servants and Canadians in general were losing faith in the curiosity-driven model of health research (www.theglobeandmail.com /news/opinions/article1138809.ece.).

More research dollars, he wrote, should be targeted toward national health priorities: "Some object philosophically to this approach, but it is absolutely necessary. In areas as vital to its national interests, Canada's research should take a back seat to no one and no country."

These sentiments appear to be shared by government officials in the United Kingdom, where, beginning in the 1960 s, research money has been gradually shifting away from curiosity-driven projects. This has raised the ire of many British researchers. A survey of UK scientists published in 2008 found that many believed the growing focus on achieving short-term goals was stifling innovation, inhibiting the freedom to change direction during research projects and driving researchers toward work that yielded predictable results instead of major breakthroughs ( $\mathrm{J}$ Biomed Discov Collab 2008;3:3). Furthermore, some scientists admitted in the survey to "gaming" the system applying for funding in one area but conducting research in another.

The paper noted that in some fields of medicine, such as cardiology, the majority of practical innovations had their origins in basic research - citing echocardiography, cardiopulmonary bypass and the discovery of the effect on blood pressure as examples.

"These three discoveries are unlikely to have been made if they had demanded goal-driven research proposals with tight time scales," states the study. "The objectives were mainly problem-solving, the funding support bore little relation to the likelihood of success, the results radically changed accepted thinking; there was no clear time-frame, but a need to understand a problem. Many other key developments have followed similar tortuous paths, such as the role of aspirin, the structure of haemoglobin, the LASER, molecular biology, and coronary angiography, all of which led to outcomes that were not envisaged at the outset."

In the United States, however, there has been an increased interest in basic research and President Barack Obama announced in 2009 that he intends to double expenditures on such science.

Nobel laureate John Polanyi, a professor of chemistry at the University of Toronto in Ontario, praised Obama for this commitment in an April 2009 essay (v1.theglobeandmail.com/servlet/story/ RTGAM.20090429.wcoscience30/BNS tory/specialComment). He had harsher words for the Canadian government, scolding it for its timid approach to funding curiosity-driven research.

Obama's claim that basic research is scientific capital, wrote Polanyi, "stands as a rebuke to those in this country who regard basic science as cash-in-hand, to be directed to the short-term. But governments that treat basic science as a current account to be drawn on will soon encounter a law of diminishing returns. Unwilling to replenish the store of knowledge, they will lower their buckets into the well until they come up dry." - Roger Collier, CMAJ

DOI:10.1503/cmaj.109-3241

Second of a series on dividing the research pie.

Part I: Subjective factors often influence outlays (CMAJ 2010. DOI:10.1503/cmaj.109-3238). 